\title{
DETERMINATION OF CINNAMIC ACID IN HUMAN URINE BY FLOW INJECTION CHEMILUMINESCENCE
}

\author{
Xuemei Fan*, Shumin Wang, Zhikui Su, Fengying Chen, Yanfeng Liu and Ping Liu \\ Department of Chemistry and Chemical Engineering, Shuoluo University, Shuoluo 726000, P. R. China \\ Xingwang Zheng \\ School of Chemistry and Material Science, Shaanxi Normal University, Xi'an 710062, P. R. China \\ Fengling Cui \\ College of Chemistry and Environment Science of Henan Normal University, Xinxiang 453007, P. R. China
}

Recebido em 21/2/11; aceito em 11/4/11; publicado na web em 10/6/11

\begin{abstract}
It was found that cinnamic acid can react with potassium permanganate in the acidic medium and produce chemiluminescence, which was greatly enhanced by glyoxal. Under the optimum conditions, the linear range for the determination of cinnamic acid was $1.0 \times 10^{-8}$ to $1.0 \times 10^{-4} \mathrm{~mol} \mathrm{~L}^{-1}$ with a detection limit of $8.0 \times 10^{-9} \mathrm{~mol} \mathrm{~L}^{-1}$, the relative standard deviation was $1.7 \%$ for $2.0 \times 10^{-6} \mathrm{~mol} \mathrm{~L}^{-1}$ cinnamic acid solution in nine repeated measurements. This method was found to be novel、simple、 fast and sensitive, it was successfully applied to the determination of cinnamic acid in human urine. Furthermore, the possible reaction mechanism was also discussed.
\end{abstract}

Keywords: flow injection chemiluminescence; potassium permanganate; cinnamic acid.

\section{INTRODUCTION}

Cinnamic acid is an important substance because it is widely used in perfume, food, photographic, polymer and pharmaceutical industries, as well as for clinical and toxicological Studies. ${ }^{1}$ Until now, many methods have been reported for its determination, such as titrimetry, ${ }^{2,3}$ differential-pulse polarography, ${ }^{4}$ spectrophotometry, ${ }^{5}$ mass spectrometry, ${ }^{6}$ HPLC, ${ }^{7}$ electrokinetic capillary chromatography, ${ }^{8}$ capillary electrophoresis, ${ }^{9}$ gas chromatography ${ }^{10}$ and liquid chromatography ${ }^{11}$. However, there are many disadvantages over these methods, such as long-response time, reagent consumption, complicated operation, etc. ${ }^{12}$

Chemiluminescence (CL) is defined as the emission of electromagnetic radiation (usually in the visible or near-infrared region) produced by a chemical reaction. Since the appearance of the highly sensitive photomultiplier tube in the 1950s, CL has been known as a powerful and important analytical technique for its advantages such as higher sensitivity, lower detection limits, wider linear ranges and simpler instrument (no excitation light source and no spectroscope).$^{13}$ Though the CL have many advantages, normally the amount of energy released during a chemical reaction dissipates as heat, therefore the chemiluminescence reagents having been investigated was limited. At present, the chemiluminescence reagents named luminol, ${ }^{14-16}$ lucigen, ${ }^{17,18}$ peroxidate, ${ }^{19}$ tris(2,2-bipyridyl)ruthenium(II) $)^{20,21}$ and potassium permanganate ${ }^{22-25}$ have been widely used in analytical chemistry. Up until now, only one article had been published for the determination of cinnamic acid by CL method, and it was based on $\mathrm{Ru}$ (bipy) ${ }_{3}{ }^{2+}-\mathrm{KMnO}_{4}$ System. ${ }^{26}$ However, this method needed expensive reagent, furthermore, the linear ranges was narrower. Consequently, development of a more novel CL detection procedure for cinnamic acid analysis should be of interest.

In our laboratory, glyoxal was found to enhance the CL emission intensity by the reaction of cinnamic acid with $\mathrm{KMnO}_{4}$ in sulfuric acid medium. Based on this reaction, we developed a novel flow injection

*e-mail: fanxuemei527@163.com chemiluminescence method for the determination of cinnamic acid. Compared with the previous reported chemiluminescence method, the present method was inexpensive, sensitive and showed wider calibration ranges. Furthermore, the possible reaction mechanism was also discussed in this paper.

\section{EXPERIMENTAL}

\section{Apparatus}

The IFFM-E flow injection CL analyzer (Xi' an Remex Electronic Instrument High-Tech Ltd., China) was equipped with an automatic injection system and a detection system. The schematic diagram of the CL flow system employed was shown in Figure 1. PTFE tube (0.8 $\mathrm{mm}$ i.d.) was used to connect all of the components in the flow system. The photomultiplier tube was operated at $-600 \mathrm{~V}$, the flow cell was a coil of glass tube that was positioned in front of the detection window of the PMT. The CL signal was treated with a personal computer.

\section{Reagents}

All chemical reagents were of analytical grade and were purchased from Xi' an Chemical Reagent Factory(Xi'an, China). All solutions were made in ultrapure water purified in a Milli-Q system (Millipore, Sartorius, Germany).

The stock standard solution $\left(1.00 \times 10^{-3} \mathrm{~mol} \mathrm{~L}^{-1}\right)$ of cinnamic acid was prepared by dissolving $0.0148 \mathrm{~g}$ cinnamic acid in water. Potassium permanganate stock solution $\left(1.0 \times 10^{-2} \mathrm{~mol} \mathrm{~L}^{-1}\right)$ was prepared by dissolving potassium permanganate in water. Working solutions were prepared by appropriate dilution of stock solution with water before use. glyoxal solution $(4 \%, \mathrm{v} / \mathrm{v})$ was prepared in water.

\section{Analytical procedures}

As shown in Figure 1, at first, the reagent stream $\mathrm{KMnO}_{4}$ solution and $\mathrm{H}_{2} \mathrm{SO}_{4}$ solution used as the oxidizer mixed with cinnamic acid, 


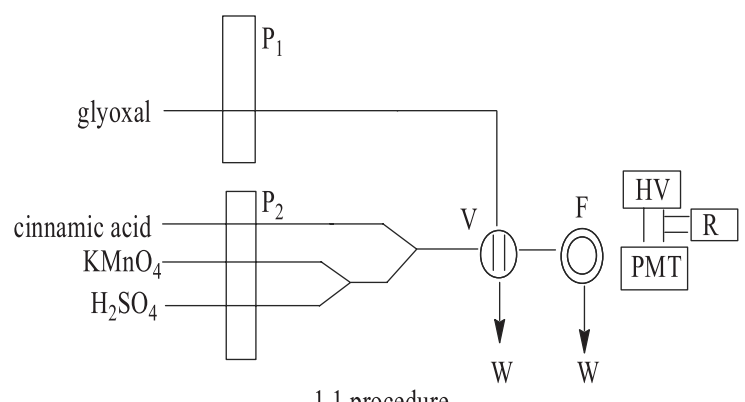

1.1 procedure

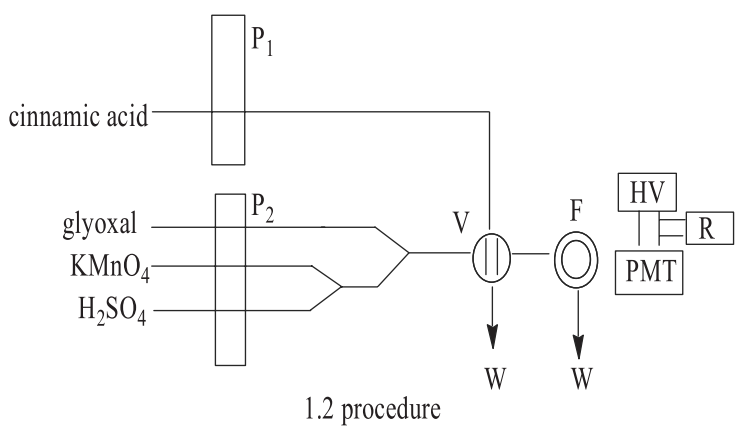

Figure 1. Schematic diagram of the flow injection analysis. P: peristaltic pump; V: six-way valve; F: flow cell; PMT: photomultiplier; HV: high voltage; W: waste; $R$ : recorder

then, the mixture was injected into glyoxal solution. At last, the mixed solution was transferred into CL cell, and the CL signal I which was proportional to the concentration of corresponding cinnamic acid was recorded.

\section{RESULTS AND DISCUSSION}

\section{Kinetic curves of $\mathrm{CL}$ reaction}

The kinetic curve was tested with a static system in the absence and presence of glyoxal, the typical CL kinetic curve was shown in Figure 2. It can be seen that the CL reaction of cinnamic acid and $\mathrm{KMnO}_{4}$ in sulfuric acid solution was so rapid that the CL intensity reached a maximum at $1.1 \mathrm{~s}$. It was also indicated that the CL intensity greatly enhanced in the presence of glyoxal.

\section{Optimization of experimental conditions}

\section{Analytical procedure}

$\mathrm{KMnO}_{4}$ act only as the oxidant for the determination of cinnamic acid in this CL system. In order to achieve the optimum procedure of determination, two analytical procedures (Figure 1) were investigated. Under the same conditions, we found that the former obtained the greater CL emission intensity than the latter. Therefore, the 1.1 procedure was used subsequently in this study.

\section{Effect of acid type and concentration}

It was observed that the $\mathrm{CL}$ signal of $\mathrm{KMnO}_{4}$-cinnamic acid system was stronger in acid solution than in neutral or basic solution. Four different acids of different concentrations were used as the mediums, the results were shown in Table 1. The results showed maximum $\mathrm{CL}$ intensity was obtained with $0.05 \mathrm{~mol} \mathrm{~L}^{-1} \mathrm{H}_{2} \mathrm{SO}_{4}$. The effect of $\mathrm{H}_{2} \mathrm{SO}_{4}$ concentration on the $\mathrm{CL}$ intensity of this system was shown in Figure 3.

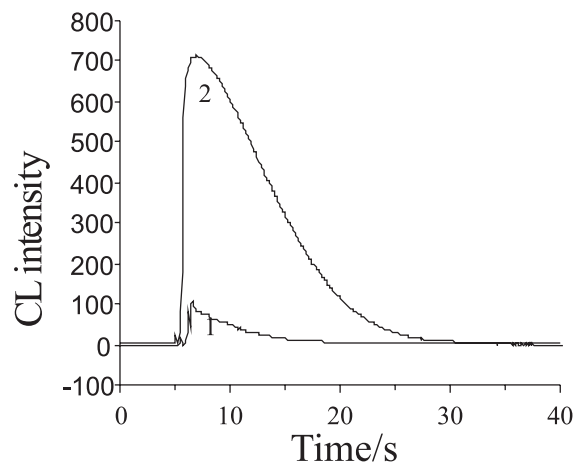

Figure 2. Kinetic curves of chemiluminescence systems. Curve 1: $1 \mathrm{~mL} 5 \times 10^{-4}$ mol L-1 $\mathrm{KMnO}_{4} ; 1 \mathrm{~mL} 0.05 \mathrm{~mol} \mathrm{~L}^{-1} \mathrm{H}_{2} \mathrm{SO}_{4} ; 1 \mathrm{~mL} 4.5 \times 10^{-5} \mathrm{~mol} \mathrm{~L}^{-1}$ cinnamic acid. Curve 2: Curve $1+1 \mathrm{~mL} 4 \%(\mathrm{~V}: \mathrm{V})$ glyoxal

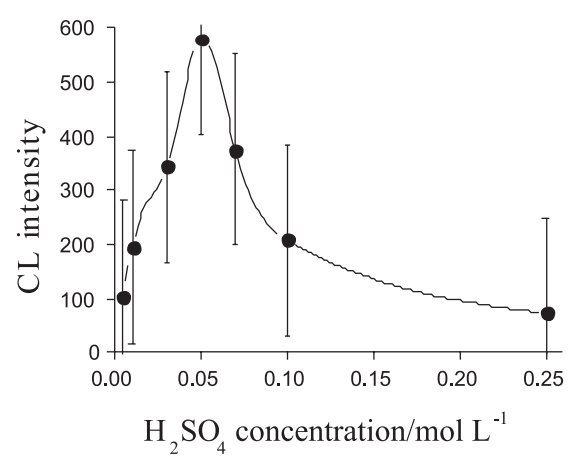

Figure 3. Effect of $\mathrm{H}_{2} \mathrm{SO}_{4}$ concentration on the CL intensity. Conditions: $\mathrm{KMnO}_{4} 5 \times 10^{-4} \mathrm{~mol} \mathrm{~L}^{-1}$; glyoxal $4 \%(\mathrm{~V}: \mathrm{V})$; cinnamic acid $2.2 \times 10^{-5} \mathrm{~mol} \mathrm{~L}^{-1}$;

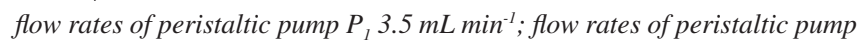
$P_{2} 2.0 \mathrm{~mL} \mathrm{~min}^{-1}$

Table 1. Effect of medium on the CL intensity

\begin{tabular}{lcc}
\hline Media & Maximum CL intensity & Optimum concentration $\left(\mathrm{mol} \mathrm{L}^{-1}\right)$ \\
\hline $\mathrm{HCl}$ & 490 & 1 \\
$\mathrm{H}_{2} \mathrm{SO}_{4}$ & 578 & 0.05 \\
$\mathrm{H}_{3} \mathrm{PO}_{4}$ & 170 & 1.5 \\
$\mathrm{HNO}_{3}$ & 370 & 1.5 \\
\hline
\end{tabular}

Effect of $\mathrm{KMnO}_{4}$ concentration

$\mathrm{KMnO}_{4}$ is the important oxidant for the determination of cinnamic acid in this CL system. In order to investigate the effect of the concentration of $\mathrm{KMnO}_{4}$ on the CL intensity. The effect of $1.0 \times 10^{-5}$ to $1.0 \times 10^{-3} \mathrm{~mol} \mathrm{~L}^{-1} \mathrm{KMnO}_{4}$ was examined, and the results was shown in Figure 4. It can be observed that the CL intensity increased with increasing $\mathrm{KMnO}_{4}$ concentration up to $5.0 \times 10^{-4} \mathrm{~mol} \mathrm{~L}^{-1}$. Larger concentration of $\mathrm{KMnO}_{4}$ could lower the CL intensity. Thus, 5.0 $010^{-4}$ $\mathrm{mol} \mathrm{L}^{-1} \mathrm{KMnO}_{4}$ was used in the work.

\section{Effect of glyoxal concentration}

The primary investigation found that glyoxal could enhance the CL intensity of cinnamic acid with $\mathrm{KMnO}_{4}$ in acidic medium. The effect of the concentration of glyoxal on the CL intensity was studied in the range of $0.5-10 \%$ and the result was shown in Figure 5. It showed that the CL intensity increased with increasing glyoxal concentration up to $4 \%(\mathrm{~V} / \mathrm{V})$. When the concentration of glyoxal continued increasing, the CL intensity keeped constant basically. Therefore, $4 \%(\mathrm{~V} / \mathrm{V})$ glyoxal was used in subsequent experiments. 


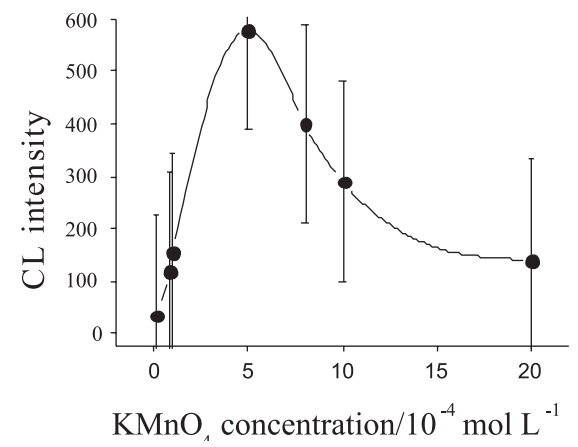

Figure 4. Effect of $\mathrm{KMnO}_{4}$ concentration on the CL intensity. Conditions: $\mathrm{H}_{2} \mathrm{SO}_{4} 0.05 \mathrm{~mol} \mathrm{~L}^{-1}$; glyoxal $4 \%$; cinnamic acid $2.2 \times 10^{-5} \mathrm{~mol} \mathrm{~L}^{-1}$; flow rates of peristaltic pump $P_{1} 3.5 \mathrm{~mL} \mathrm{~min}^{-1}$; flow rates of peristaltic pump $P_{2} 2.0 \mathrm{~mL} \mathrm{~min} \mathrm{~m}^{-1}$

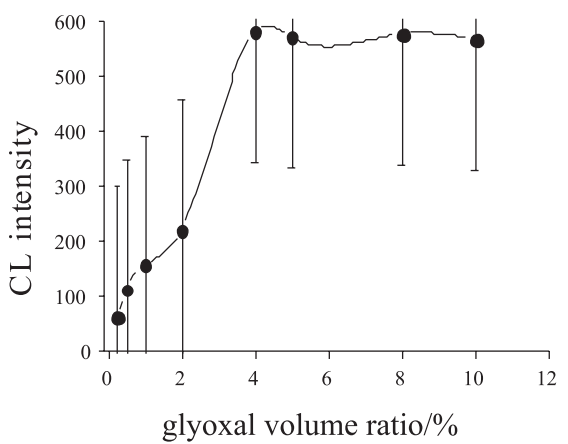

Figure 5. Effect of glyoxal concentration on the CL intensity. Conditions: $\mathrm{KMnO}_{4} 5 \times 10^{-4} \mathrm{~mol} \mathrm{~L}^{-1} ; \mathrm{H}_{2} \mathrm{SO}_{4} 0.05 \mathrm{~mol} \mathrm{~L}^{-1}$; cinnamic acid $2.2 \times 10^{-5} \mathrm{~mol} \mathrm{~L}^{-1}$; flow rates of peristaltic pump $P_{1} 3.5 \mathrm{~mL} \mathrm{~min}^{-1}$; flow rates of peristaltic pump $P_{2} 2.0 \mathrm{~mL} \mathrm{~min}^{-1}$

\section{Effect of surfactants}

The effect of some surfactants (non-ionic PEG, cationic CTMAB and anionic SDBS) on the CL intensity was tested. The results showed that SDBS lowered the CL intensity about for seven times, CTMAB and PEG had no effect on the analytical signal. Therefore, these surfactants were not used for the further work.

\section{Effect of flow rate}

The flow rates of peristaltic pump $\mathrm{P}_{1}$ and $\mathrm{P}_{2}$ were investigated. It was found that the CL intensity increased with increasing the flow rate of $\mathrm{P}_{1}$ and the $\mathrm{CL}$ intensity reached the maximum at $3.5 \mathrm{~mL} \mathrm{~min}{ }^{-1}$ and then keeped constant. The CL intensity also increased with the increasing flow rate of $\mathrm{P}_{2}$ and the $\mathrm{CL}$ intensity reached the maximum at $2.0 \mathrm{~mL} \mathrm{~min}^{-1}$. So 3.5 and $2.0 \mathrm{~mL} \mathrm{~min}^{-1}$ were, respectively, selected for the flow rates of $\mathrm{P}_{1}$ and $\mathrm{P}_{2}$.

Linear response range, detection limit and precision

Under the above optimum conditions, the CL intensity versus cinnamic acid concentration was measured. The regression equation, correlation coefficients and the detection limit were summarized in Table 2. The reproducibility was examined using $2.0 \times 10^{-6} \mathrm{~mol} \mathrm{~L}^{-1}$ cinnamic acid $(n=9)$ and the relative standard deviation was $1.7 \%$.

\section{Interference}

Under the selected experimental conditions, the interference tests of some foreign species were performed. The results showed that 1000-fold $\mathrm{K}^{+}, \mathrm{Na}^{+}, \mathrm{NO}_{3}^{-}$, EDTA, 800-fold $\mathrm{Zn}^{2+}, \mathrm{Ca}^{2+}, \mathrm{Cd}^{2+}, \mathrm{Al}^{3+}, \mathrm{Mg}^{2+}$, $\mathrm{Ni}^{2+}, \mathrm{Pb}^{2+}, \mathrm{Ba}^{2+}, \mathrm{NH}_{4}^{+}, \mathrm{CO}_{3}{ }^{2-}, \mathrm{SO}_{4}{ }^{2-}, \mathrm{PO}_{4}{ }^{3-}, 500$-fold $\mathrm{Cl}^{-}, \mathrm{Fe}^{2+}, \mathrm{Cu}^{2+}$, $\mathrm{Cr}^{3+}, \mathrm{Fe}^{3+}, \mathrm{Co}^{2+}$, starch, fructose glucose, lactose, 100-fold urea, uric acid, 50-fold methanol, ethanol and two fold ascorbic acid were not interfered with the determination of $2.0 \times 10^{-6} \mathrm{~mol} \mathrm{~L}^{-1}$ cinnamic acid at the confidence level of $95 \%$. So, the method had a high selectivity.

\section{Application}

The human urine sample was obtained from a healthy person and the proposed method was directly applied to the determination of cinnamic acid in human urine without any retreatment. In order to decrease the background of the determination, the sample was diluted for 25 -fold. The spiked samples were prepared by mixing the standard and the diluted sample. By this method, the determination results (Table 3 ) were close to those obtained by the LC methods. ${ }^{27}$ Compared with the previous reported method for the determination of cinnamic acid, the advantages of using the present method had a good reproducibility and sensitivity.

\section{Possible reaction mechanism}

It was reported that $\mathrm{KMnO}_{4}$ could react with some reductants in the presence of formaldehyde to produce ${ }^{1} \mathrm{O}_{2}{ }^{1} \mathrm{O}_{2}\left({ }^{1} \mathrm{~g}^{1} \mathrm{~g}\right)$, a complex oxygen molecule of single state, which could transform into ${ }^{3} \mathrm{O}_{2}\left({ }^{3} \mathrm{~g}\right)$, a triplet state oxygen. During the transformation, it could produce $\mathrm{CL}$ and the formaldehyde could accelerate oxidation reaction rate. ${ }^{28}$ Thus, the cinnamic acid could also react with $\mathrm{KMnO}_{4}$ to produce CL and the CL reaction could be accelerated by glyoxal.

Based on the above discussions, the possible reaction mechanism was suggested as following:

Table 2. Analytical parameters for the determination of cinnamic acid

\begin{tabular}{lll}
\hline Mem Detection & Line range $\left(\mathrm{mol} \mathrm{L}^{-1}\right)$ & Regression equation, $\left.\mathrm{C}(\mathrm{mol} \mathrm{L})^{-1}\right)$ \\
\hline $1.0 \times 10^{-8} \sim 1.0 \times 10^{-5}$ & $\mathrm{I}=90.61+0.605 \times 10^{7} \mathrm{C}$ & 0.9992 \\
$1.0 \times 10^{-5} \sim 1.0 \times 10^{-4}$ & $\mathrm{I}=-177.46+340.64 \times 10^{5} \mathrm{C}$ & 0.9989 \\
\hline
\end{tabular}

$I$ is the $\mathrm{CL}$ intensity and $C$ is the concentration.

Table 3. The result of recovery $(n=7)$

\begin{tabular}{|c|c|c|c|c|c|c|}
\hline \multirow{2}{*}{ Sample } & \multirow{2}{*}{ Added $/ \mu \mathrm{M}$} & \multirow{2}{*}{ Found/ $\mu \mathrm{M}$} & \multicolumn{2}{|c|}{$\mathrm{RSD} / \%$} & \multirow{2}{*}{$\begin{array}{l}\text { Relative difference } \\
\qquad(\mathrm{CL}-\mathrm{LC} \%)\end{array}$} & \multirow{2}{*}{ Recovered/\% } \\
\hline & & & CL method & LC method & & \\
\hline Urine & 4.00 & 4.35 & 4.28 & 3.0 & 1.63 & 108.8 \\
\hline \multirow[t]{2}{*}{ (Dilute 25 fold) } & 6.00 & 6.87 & 6.65 & 2.7 & 3.31 & 114.5 \\
\hline & 8.00 & 7.64 & 7.83 & 2.4 & 2.43 & 95.5 \\
\hline
\end{tabular}


$\mathrm{MnO}_{4}{ }^{-}+$glyoxal $+\mathrm{H}^{+}+$cinnamic acid $\rightarrow{ }^{1} \mathrm{O}_{2}\left({ }^{1} \Delta \mathrm{g}\right)+\mathrm{Mn}(\mathrm{II}-\mathrm{IV})+\mathrm{H}_{2} \mathrm{O}$ + products

$2^{1} \mathrm{O}_{2}\left({ }^{1} \Delta \mathrm{g}\right) \rightarrow{ }^{1} \mathrm{O}_{2}{ }^{1} \mathrm{O}_{2}\left({ }^{1} \Delta \mathrm{g}^{1} \Delta \mathrm{g}\right){ }^{1} \mathrm{O}_{2}{ }^{1} \mathrm{O}_{2}\left({ }^{1} \Delta \mathrm{g}^{1} \Delta \mathrm{g}\right) \rightarrow 2^{3} \mathrm{O}_{2}\left({ }^{3} \Sigma \mathrm{g}\right)+\mathrm{h} v$

\section{CONCLUSION}

A novel flow injection analysis method has been proposed, it was based on that cinnamic acid can react with potassium permanganate in the acidic medium and produce chemiluminescence, which was greatly enhanced by glyoxal. Comparing to the previous methods for determination of cinnamic acid, the proposed method showed its advantages in simplicity, sensitivity, selectivity and avoided expensive reagent consumption. This method was successfully used in the determination of cinnamic acid in human urine.

\section{ACKNOWLEDGEMENTS}

This project was financially supported by the Science Foundation of Shuoluo College, P. R. China (No. 10SKY015) and National Natural Science Foundation of China (No. 30970696).

\section{REFERENCES}

1. Grayson, M.; Encyclopedia of Chemical Technology, Wiley: New York, 1981.

2. Majer, J. R.; Ellis, M; Anal. Chim. Acta 1984, 165, 237.

3. Chinese Pharmacopoeia, People Hygiene Press : Beijing, 1995, chap. 2.

4. Ferreira, V. S.; Melios, C. B.; Zanoni, M. V.; Stradiotto, N. R.; Analyst 1996, 121, 263.

5. Bounias, M.; Daurade, M. H.; Lizzi, Y.; Analysis 1989, 17, 201.

6. Zhang, J.; Chen, M.; Ju, W. Z.; Liu, S. J.; Xu, M. J.; Chu, J. H.; Wu, T.; J. Pharm. Biomed. Anal. 2010, 51, 685.
7. Sladkovský, R.; Solich, P.; Opletal, L.; J. Pharm. Biomed. Anal. 2001, 24, 1049.

8. Lu, Y.; Wu, C.; Yuan, Z.; Fitoterapia 2004, 75, 267.

9. Li, L. J.; Feng, J.; Chen, W.; Chinese J. Anal. Chem. 2007, 35, 401.

10. Biemer, T. A.; Asral, N.; Albanese, J. A.; J. Chromatogr. 1992, 623, 395.

11. Cheng, J.; Li, Y. S.; Roberts, R. L.; Walker, G.; Talanta 1997, 44, 1807.

12. Qu, P.; Yan, S. C.; Lu, H.; Lu, Z. H.; Microchim. Acta 2008, 163, 321.

13. Li, B. X.; Guo, L. L.; Xu, C. L.; Ma, L. M.; Spectrochim. Acta, Part A 2008, 71, 892.

14. Lu, J. Q.; He, W. W.; Zhou, X. W.; Chin. Chem. Lett. 2006, 17, 1233.

15. Ensafi, A. A.; Khayamian, T.; Hasanpour, F.; J. Pharm. Biomed. Anal. 2008, 48, 140.

16. Nalewajko, E.; Wiszowata, A.; Kojło, A.; J. Pharm. Biomed. Anal. 2007, 43, 1673.

17. Uketa, H.; Sarker, A. K.; Kawana, D.; Sawamura, M.; Anal. Chim. Acta 2001, 438, 137.

18. Afanasev, I. B.; Ostrakhovitch, E. A.; Mikhalchik, E. V. M.; Korkina, L. G.; Luminescence 2001, 16, 305.

19. Nakashima, K.; Kawaguehi, S.; Givens, R. S.; Anal. Sci. 1990, 6, 833.

20. Anastos, N.; Barnett, N. W.; Lewis, S. W.; Gathergood, N. S. J.; NoelSims, D.; Talanta 2005, 67, 354.

21. Gorman, B. A.; Barnett, N. W.; Anal. Chim. Acta 2005, 541, 119.

22. Barnett, N. W.; Hindson, B. J.; Jones, P.; Smith, T. A.; Anal. Chim. Acta 2002, 451, 181

23. Zhuang, Y. F.; Song, H. L.; J. Pharm. Biomed. Anal. 2007, 44, 824.

24. Li, L. N.; Li, N. B.; Luo, H. Q.; Anal. Sci. 2005, 21, 963.

25. Zhang, D. Y.; Ma, Y. J.; Zhou, M.; Li, L.; Chen, H.; Anal. Sci. 2006, 22, 183.

26. Han, H. Y.; He, Z. K.; Zeng, Y. E.; Anal. Chim. Acta 1999, 402, 113.

27. Luo, G. M.; Yang, W. L.; Lai, X. W.; Xie, S. X.; Liu, X. W.; YaowuFenxi Zazhi 1996, 16, 338.

28. He, Y. H.; Lu, J. R.; Chin. J. Anal. Chem. 2002, 30, 598. 